\title{
Talent Training Model Construction of MTCSOL Program Based on Outcome-Based Education
}

\author{
Wu Cai \\ Overseas Education College, Collaborative Innovation Center for Peaceful Development of Cross-Strait Relations \\ Xiamen University \\ Xiamen, China \\ totc1003@163.com
}

\begin{abstract}
With the rapid development of the MTCSOL (Master of Teaching Chinese to Speakers of Other Languages) program, how to improve its quality has become a major theme. The paper first introduces the theory and applications of outcome-based education, and then demonstrates the current situation and important issues of MTCSOL program. The talent training model construction of MTCSOL program based on outcome-based education and specific suggestions for government, university administrators and teachers in the implementation process of MTCSOL program are both proposed.
\end{abstract}

Keywords-MTCSOL program; outcome-based education; talent training model; construction

\section{INTRODUCTION}

In recent years, with the rapid development of China's economy, the demand for Chinese language talents in the world has been expanding. Therefore the number of Chinese L2 (second language) learners has continued to increase. Statistically, there are 100 million Chinese L2 learners outsides of China. Meanwhile, more and more foreign students come to China to learn Chinese. In this context, the demand for CSL (Chinese as a second language) teachers is also increasing. In order to supplement the shortage of CSL teachers, in 2007, 24 Chinese graduate education institutions first set up MTCSOL (Master of Teaching Chinese to Speakers of Other Languages) program. The project is growing at an amazing speed. By 2016, 110 universities in Mainland China had opened MTCSOL program.

The MTCSOL program has transported a large number of professional Chinese language teaching talents for the international Chinese language education in the world. Even some scholars had pointed out that the large scale of the training of international Chinese language teachers started from the setting of the MTCSOL program [1]. Teaching Chinese to the Speakers of Other Languages is an interdisciplinary program, which includes interdisciplinary language, literature, history, philosophy, politics, economy, culture, psychology, education and so on [2]. It is a very high demand for the ability of students in the MTCSOL program, and it also poses great challenges to the international Chinese language education project. This is a very high demand for the ability of Chinese master students in the international Chinese language education, and it also poses great challenges to the MTCSOL program. On the one hand, in the training process in this program, teaching goal formulation, curriculum content setting, internship arrangement and employment arrangement are very critical, which directly affects teaching achievement. On the other hand, because of the interdisciplinary nature of the MTCSOL program, more and more interdisciplinary teachers have joined in the MTCSOL program's teaching team, making the educators' team showing diversity and complexity characteristics. It is an important issue for government, university administrators and teachers to help the students of MTCSOL program get the best learning outcomes.

Firstly, this study illustrates the theory of outcome-based education and its application, and then introduces the current situation and important issues of MTCSOL program. In the third section, the talent training mode of MTCSOL program based on the principles of outcome-based education is proposed. Particularly, in the fourth section, the paper presents specific suggestions for government, university administrators and teachers in the implementation process of MTCSOL program.

\section{LITERATURE REVIEW OF OUTCOME-BASED EDUCATION}

\section{A. The Development of Outcome-based Education}

Mitchell and Spady first proposed the concept of outcomebased education. They thought there were four major contributions which schools had been expected to make to these adult characteristics:(1) to facilitate and certify the achievement of technical competence; (2) to encourage and enhance the fullest possible development of physical, emotional, and intellectual skills and abilities; (3) to generate and support social integration among individuals across cultural groups and within institutions; (4) to nurture and guide each student's sense of social responsibility for the consequences of his/her own personal actions, and for the character and quality of the groups to which the student belongs[3]. Then Spady clarified outcome-based education by outcome-based instructional management [4] and organizing the results [5]. In 1994, a book of "Outcome-Based Education: Critical Issues and Answers" [6] was published to answer the key issues of outcome-based education by Spady.

Different scholars have evaluated the outcome-based education from various views. Driscoll and Wood put forward outcome-based education was an educational mode, in which teaching and assessment were focused on student's learning 
outcomes, which could promote the continuous attention of the school and was responsible for the learning of students [7]. Tavner believed that the outcome-based education was a student centered education method, focusing on the expected results of learning brought by the teaching [8]. Leung emphasized that outcome-based education paid attention to the ability that students could really master after completing the learning process [9]. Therefore, under the guidance of outcome-based education theory, educators must have a clear conception of their students' abilities and levels to be achieved, and then seek for a suitable educational structure to ensure that students achieve these desired goals. In other words, the outcome-based education is a kind of talent training mode, which is a student-centered teaching method, and focuses on the demonstration to measure the students' achievements.

Considering the characteristics of OBE, some scholars have pointed out that the outcome-based education and traditional education (input based and process based education) had the following differences [10]: (1) In the outcome-based education, students' learning goals, courses, teaching materials, teaching, evaluation and graduation standards are guided by results; the school should provide students with as many opportunities as possible about different forms of expansion and application; take the final results as the student's study and practice; on the basis of effectiveness, students must confirm what they can do and have clear results when they finish the project; learnerscentered, the teachers constantly combine the life situation and help the students to learn by teamwork and synergy; emphasis on cooperative learning; results, multiple assessment of outcome oriented, and emphasis on evidence.(2) In the traditional education, emphasizing the students' learning based on the calendar, the established curriculum, learning process, learning time; according to the calendar and schedule, and restrict the development of the chance of success; to use the average sores to measure student achievement; to score as the standard; the textbook centered or the teacher centered; content oriented, more emphasis on competition; with pen and paper test.

\section{B. The Core Elements of Outcomes-Based Education}

Spady put forward the core elements of outcome-based education[11]: (1) Paradigm: at the beginning, we need to have a clear framework to understand what abilities students should have, then plan and implement education system organization, curriculum, teaching and evaluation index clearly.(2) Purposes: to ensure that students can have the knowledge, ability and quality to achieve success before graduation (after completing the study project); create situations and opportunities for students to maximize their learning results.(3) Premise: all students can learn and succeed, but not necessarily at the same time or using the same method (depending on students' learning level and learning style). Successful learning will bring more successful experience. The conditions for the success of the school control have a direct impact on the success of the students. (4) Principles: clarity of focus, expanded opportunities, high expectations and design down; (5)Practice: including defining outcomes, designing curriculum, deliver instruction, document results, and determine advancement.
Therefore, Because of these core elements, the outcomebased education is different from the traditional education. All the resources are for the students' learning outcomes.

\section{The Definition of Outcome}

In the field of education, the emergence of the word "outcome" has undergone evolution. At the earliest, Tyler proposed the goal of education, which was the change of behavior habits (mine, thought and action) that educational institutions tried to bring to students [12]. Mager believed that educational goals were too broad and it should be instead of teaching objectives, that was, what the learners could do after a specific course of learning [13]. Eisner demonstrated the concept of outcome for the first time. He thought that outcome should be finally obtained by students after learning, no matter it was deliberate or unintentional, there was no need to match all strict standards of behavior objectives [14].

Spady divided the outcome-based education into the traditional OBE, the transitional OBE and the transformational OBE. The traditional outcome was to pay attention to the skill and structural performance of the subject, with the emphasis on memory and understanding. The transitional outcome emphasized the performance of high-level and unstructured. Compared with the outcome of traditional type, it was more necessary to integrate the knowledge and ability in different disciplines. The transformational outcome highlighted the complex performance outcome and emphasized the future orientation of learning outcome was to have the knowledge, ability and characteristics of future citizens [15].

Some scholars pointed out in the field of education, the outcomes could be divided into three different levels [16] [17]: (1) the level of teaching institutions which assessment agencies related to the performance of quality assurance, it needed to collect whether students meet the learning objectives (employment, student education, occupation career changes etc.); (2) the teacher level that focused on the effectiveness of curriculum and teaching. (3) the student level which manifested the specific, measurable goals and results that should be acquired after learning, including changes in knowledge, skills, abilities, and attitudes.

\section{The Application of Outcome-based Education}

There are many countries and regions used Outcome-based education in the different branches of education.

United States: in the late 1990s, the quality assurance measures of all kinds of higher education in the United States took the results of students' learning outcome as an important assessment index. It could be said that in the United States, outcome-based methods are mainly used in the evaluation system of higher education and the study of college students.

Europe: "learning outcome" is an important project of the "Bologna process" (European higher education reform program) and constitutes EU Common Curriculum Model of the development of higher education; Kennedy proposed that the learning outcomes of the university system reduced the gap, promoted the integration of European higher education and was of great significant [18]. 
South Africa: in the middle of 1990s, in order to improve the quality of education and increase the technology labor force, the theory of outcome-based education was introduced into South Africa [19].

Malaysia: outcome-based education has been integrated into all levels of the education system in Malaysia, especially becomes one of the most widely considered topics in educational sector of higher education [20].

Hongkong: in 2007, the University of Hong Kong considered outcome-based approaches as the important measure of educational reform in Hongkong. Hongkong's subsidized universities by University Grants Committee have responded and made use of the outcome-based method gradually to renew the university undergraduate courses.

In addition, outcome-based education is also widely used in Australia, Canada and other regions and countries.

\section{THE CURRENT SITUATION AND IMPORTANT ISSUES OF MTCSOL PROGRAM}

International Chinese language education is a young subject. It develops rapidly and also has many problems at the same time.

\section{A. Geographical Location Distribution}

At present, most of the universities that set up MTCSOL program in Mainland China are mainly in major cities such as Beijing, Shanghai and Guangzhou. Some provinces such as Qinghai, Tibet and Ningxia do not have this kind of master's degree. Therefore the big cities have a strong appeal to the international Chinese education resources. This is related to the economic development of the big cities and the attraction of foreign students. There are 12 universities setting up MTCSOL program in Beijing which are Renmin University of China, Beijing Institute of Technology, Peking University, Beijing Normal University, Capital Normal University, Beijing Foreign Studies University, Beijing Language and Culture University, Communication University of China, Minzu University of China, Beijing International Studies University, China University of Petroleum, University of International Business and Economics. There are 8 MTCSOL programs in the universities in Shanghai which are Fudan University, East China Normal University, Shanghai International Studies University, Shanghai Normal University, Shanghai Jiao Tong University, Shanghai University of Finance and Economics, Shanghai University and Tongji University. In Guangzhou, there are 5 universities in Guangzhou which are Zhongshan University, Jinan University, South China Normal University, Guangdong University of Foreign Studies and Guangzhou University.

\section{B. The Majority of Full-time Program}

In the 110 universities in Mainland China which had opened MTCSOL program, only 21 universities have part time program. It shows that the master program of MTCSOL is more inclined to get a longer training time in order to better cultivate the teaching and academic ability of master students.
Meanwhile, the part time MTCSOL program can create more chances to the people who are interested in this program. The 21 universities are Wuhan University, Hebei Normal University, Shenyang Normal University, Tongji University, Soochow University, Jiangsu University, Zhejiang University of Science and Technology, China University of Petroleum (Hua Dong), Ludong University, Yantai University, Henan Polytechnic University, Huazhong University of Science and Technology, Hubei University of Technology, Southwest University of Science and Technology, Hubei University, Xinjiang University, Yangzhou University, Xinjiang Normal University, Xi'an Petroleum University, LanZhou JiaoTong University and Sichuan Normal University.

\section{Different Training Units}

The different universities opened the MTCSOL program in different management system. More specifically, the training units are different. Some MTCSOL programs are in the foreign languages institutes which are in charge of international Chinese and dissemination of Chinese culture, such as Minzu University of China, Xiamen University, Nanjing Normal University and so on. It is helpful to add the communication between MTCSOL master student and foreign students. The master student of MTCSOL can understand the difficulties of foreign students in learning Chinese and link the learning with the reality of life.

Some MTCSOL programs are in the colleges of humanities, such as Shenyang Normal University, Yangzhou University and so on. Because of the training concepts in different units are not the same, the training outcomes will also be very different.

\section{Different Internship Opportunities}

Though there are 110 colleges and universities having MTCSOL program, there are great differences in internship opportunities. Taking Xiamen University as an example, the students of MTCSOL programs have more internship opportunities, because there are 16 Confucius institutes of Xiamen University all around the world. But some universities have less Confucius colleges, and even there are not any Confucius colleges in these universities. Therefore it is difficult for the master students to get the chances of overseas Chinese teaching practice.

\section{E. Low Match Rate of Graduate Employment}

There is low match rate of employment in the most MTCSOL programs in Mainland China. Wu believed that the match rate of employment was generally about $20 \%$, and more than $50 \%$ was already a good level [21]. Even in Peking University which is famous university in China, the match rate of employment of MTCSOL Programs is also low. The graduates engaged in this professional work very few, and most of the graduates went to secondary school (Teaching Chinese or English), companies, state organs and so on [22]. The low match employment rate has become the main bottleneck restricting of the development of MTCSOL Programs in the recent years, 


\section{F. Different Professional Background of Teachers}

In Some universities, the teachers of MTCSOL programs are very professional. They have plenty of overseas Chinese teaching experience and good teaching ability. However, some teachers of MTCSOL programs in some universities have fewer opportunities of teaching abroad, not even taught foreign students; some teachers in colleges and universities are from many disciplines, therefore the students of MTCSOL programs can get more knowledge and skills. But in some universities, the teachers have plenty of limitations and mainly from the discipline of Chinese.

\section{The ApPlicAtion Of OUTCOME-BASEd EdUCATION IN MTCSOL PROGRAMS}

When we apply outcome-based education into MTCSOL program, we must know what is outcome for MTCSOL program. First of all, the MTCSOL students will become the CSL teachers in the future. Therefore the core competences of CSL teachers are suitable for MTCSOL student. Cai proposed six core competences of CSL teachers: (1) Chinese and foreign language knowledge and skills; (2) intercultural competence (including the ability to understand and compare Chinese culture and foreign cultures);(3) acquisition strategy of Chinese as a second language; (4) Pluralistic teaching methods (e.g. the integration of information technology); (5) professional ethics and psychological quality; (6) classroom management, adaptability and interpersonal skills[23]. The six core competences are also important for the students of MTCSOL program.

Secondly, the MTCSOL is a kind of master education so that the academic ability of the students is also important. Thirdly, MTCSOL students have a great number of chances to go abroad to teach Chinese, the interpersonal ability and practical ability are also important.

On the basis of these outcomes above, we can establish outcome-based talent training model of MTCSOL program. It consists of the following steps. First of all, confirming the outcomes of MTCSOL program; in the second, setting up the course objective which are correspond with the outcomes of the MTCSOL program; and third, using the principles of outcomebased education to the MTCSOL program, which are clarity of focus, expanded opportunities, high expectations and design down; in the end of the training mode, using multiple evaluation methods after the implement of all the teaching experience.

\section{The CONCLUSIONS AND SUGGESTIONS}

Facing the rapid development of the MTCSOL (Master of Teaching Chinese to Speakers of Other Languages) program, how to improve its quality has become a major theme. The paper first introduces the theory and applications of outcomebased education, and then demonstrates the current situation and important issues of MTCSOL program including geographical location distribution, the majority of full-time program, different training units, different internship opportunities, low match rate of graduate employment and the different background of teachers. The talent training model construction of MTCSOL program based on outcome-based education is proposed. Above all, here we will give specific suggestions for government, university administrators and teachers in the implementation process of MTCSOL program.

For the government, they must increase the opportunity for students to teach Chinese abroad and extend their service time. Most of MTCSOL program students become Chinese international teacher volunteers supported by the Confucius Institute Headquarters. Nowadays the international Chinese language teacher volunteers only have the service period of three years to teach Chinese outside of China. In fact, it is not good for the CSL learners and the volunteers themselves. Then the government should increase support for the returning volunteer teachers and help them relief from worries of applying for jobs.

For the university administrators, they also need take actions to help the students of MTCSOL program. (1) They should strengthen students' ability to explore actively. The ability of active exploration includes creative ability, reflective ability, feedback ability and evaluation ability. These abilities play an important role in the future work of MTCSOL program students. (2) They should create more opportunities to provide students with more internships chances. (3) They should make career guidance for the students of MTCSOL program.

For the teachers, there are also some advices. (1) In the recent year, there are many teachers from interdisciplinary professional background teaching the students of MTCSOL program. It must be restricted in the access threshold. For example, in the recruitment of teachers, we should put forward the teaching experience of overseas Chinese, with international vision and other conditions, which is conducive to their guidance to the students. For the teachers who have entered the MTCSOL program at the present stage, they should try to get the opportunity for them to teach foreign students. It is also necessary to organize teachers with rich Chinese teaching experience to communicate with the new teachers in the MTCSOL program. (2) The ability of teacher educators should have content (one subject content knowledge), ability of communication and reflection (with different background students communicate etc.), organizational skills (ability to teamwork effectively organize students etc.) and education skills (adjust teaching methods, the use of multimedia technology and so on) [24]. Therefore the educators of MTCSOL program should requires professional knowledge, communication skills, organizational skills, pluralistic education and skills. (3)Teacher educators of MTCSOL program are still a researcher, which requires that they have certain academic ability, and their research should be related to Chinese teaching and increase their research ability.(4) Chinese language teacher educators are also a service provider for students' internships. So they should do a good job of students' internship service.

Finally, we can also get experience from other regions. For example, there are also MTCSOL program in Taiwan area. Nowadays there are 16 universities have the program in Taiwan area. The goal of the talent training of MTCSOL program on both sides of the Taiwan Straits is consistent, which is to enable the students to master the skills of Chinese language teaching and to better promote the Chinese language 
and culture. In addition, Chinese teachers' education on both sides of the Straits is often faced with common difficulties, such as how to build better talents training mode of MTCSOL program that meets the needs of the society, how to increase students' internship opportunities and how to improve their employment rate in the related sectors of international Chinese language education. These subjects need to be discussed and solved by the academic circles of the two sides of the Straits. As a matter of fact, there have been a great number of academic cooperations in the field of Chinese language education across the Straits. For example, scholars' visits, lectures, teachers and students seminar, which had provided a good realistic basis for the communication. In the future, we should continue to strengthen the communication of talent training of MTCSOL program on both sides of the Taiwan Straits and improve the outcomes of the students of MTCSOL program.

\section{ACKNOWLEDGMENT}

This research was financially supported by 2017 Graduate Field Research Fund of Xiamen University (Grant No: 2017GF035) and 2017 Young and Middle-aged Teacher Education Research Project of Fujian Province (Grant No: JAS 170549).

\section{REFERENCES}

[1] G.S. Wang, "Reflection on the problems related to the training of master of teaching Chinese to speakers of other languages", Journal of Hubei University (Philosophy and Social Science) .Wuhan, vol.38 (4), pp.2630, 2011. (In Chinese)

[2] T.T. Zheng, “The Collaborative Innovation of the Chinese Internaitonal Education and Cultural Inheritance and Transmission-the speech on the Fourth Annual Seminar of East Asia Sinology \& First International Seminar of the New Sinology ”, Overseas Chinese Education .Xiamen, vol.4, pp.339-345, 2013. (In Chinese)

[3] D.E. Mitchell and W.G. Spady, "Organizational Contexts for Implementing Outcome Based Education”, Educational Researcher, vol.7 (7), pp.9-17, 1977.

[4] W.G. Spady, Outcome-Based Instructional Management: A Sociological Perspective. Washington, D.C :National Institute of Education, 1981.

[5] W.G. Spady, "Organizing for Result: The Basis of Authentic Restructuring and Reform”, Educational Researcher, vol.46 (2), pp.4-8, 1988.

[6] W.G. Spady, Outcome-Based Education: Critical Issues and Answers. Arlington,VA : American Association of School Administrators, 1994.

[7] A. Driscoll and S. Wood: Developing Outcomes-based AssessmentDeveloping Outcomes-based Assessment for Learner- centered Education: A Faculty Introduction. Sterling, Virginia : Stylus Publishing, 2007.

[8] A. Tavner, "Outcomes-based education in a university setting", Australasian Journal of Engineering Education, vol.2, pp.1-14, 2005.

[9] P. P-W Leung, “Outcome-Based Learning and the Quality Enhancement of University Teaching: The Practices of Chinese Teachers”Journal of Research in Education Sciences, vol.58 (4) , pp.1-35, 2013.

[10] K.C. Li, University Curriculum Development and Learning Outcome Assessment, Taiwan: Higher Education Press, 2011.

[11] W.G. Spady, Outcome-Based Education: Critical Issues and Answers. Arlington,VA : American Association of School Administrators, 1994.

[12] R.W. Tyler, Basic Principles of Curriculum Instruction, Chicago: University of Chicago Press, 1949.

[13] R. Meger, Preparing Instrucational Objectives, Belmont:David Lake Pubilshers, 1962.

[14] E.W. Eisner, The Educational Imagination, New York : Macmillan, 1979.

[15] W.G. Spady, Outcome-Based Education: Critical Issues and Answers. Arlington,VA : American Association of School Administrators, 1994.

[16] M. Tam, "The outcomes-based approach: Concepts and practice in curriculum and educational technology design”, Informed design of educational technologies in higher education: Enhanced learning and teaching, in A. D. Olofsson \& J. O. Lindberg , Eds. Hershey, PA: IGI Global, 2012, pp. 21-37.

[17] H.T. Huang, Student Learning Outcomes Assessment: Quality Assurance in American Higher Education, Beijing: Educational Science Publishing House, 2014. (In Chinese)

[18] K, Kennedy, “ Outcomes based learning: Concepts, issues and action”. unpublished, 2009.

[19] L. Chisholm, "Diffusion of the National Qualifications Framework and outcomes-based education in southern and eastern Africa”, Comparative Education, vol.43(2), pp.295-309,2007.

[20] M.G. Mohayidin, "Implementation of Outcome-Based Education in Universiti Putra Malaysia:A Focus on Students' Learning Outcomes” ,International Education Studies, vol.1(4), pp.147-160,2008.

[21] Y.H. Wu, “On some TCSOL-related theories and practice”, Journal of Yunnan Normal University(Humanities and Social Sciences) .Kunming, vol.48(1), pp.38-46, 2016. (In Chinese)

[22] S.H. Liu, "The Employment Difficulty and the Focus of the MTCSOL Program”, Journal of International Chinese Teaching, Beijing, vol.3, pp.83-89.2016. (In Chinese)

[23] W. Cai, "The Competency-Based Education: A New Perspective on CSL Teacher Training Mode Constructionhe”, Proceedings of 2nd International Conference on Humanities and Social Science (HSS 2017), Advances in Social Science, Education and Humanities Research,vol.83, pp.235-241,2017.

[24] B. Koster, M. Brekelmans, F. Korthagen and T. Wubbels "Quality requirements for teacher educators”,Teaching and Teacher Education, vol.21, pp.157-176, 2015. 